\title{
Failure to Rescue, Rescue Surgery and Centralization of Postoperative Complications: A Challenge for General and Acute Care Surgeons
}

\author{
Mauro Zago', Samantha Bozzo', Giulia Carrara', Diego Mariani² \\ 'Department of General Surgery, Minimally Invasive Surgery Unit, Policlinico San Pietro, Italy \\ ${ }^{2}$ Department of General Surgery, Legnano Hospital, Italy
}

Corresponding author: Mauro Zago, MD

Via Savona, 69 - 20144 Milano, Italy E-mail: maurozago.md@gmail.com

Received: 30.08 .2017 Accepted: 10.09 .2017

\section{Rezumat}

Imposibilitatea de salvare, chirurgia de salvare și centralizarea complicatiilor postoperatorii: o provocare pentru chirurgii generali si de urgentă

Scop: De a explora literatura de specialitate actuală în ceea ce priveşte conceptele imposibilității de salvare şi al chirurgiei de salvare, în vederea identificării elementelor cheie pentru reducerea ratei de imposibilitate de salvare şi îmbunătățirii rezultatelor, precum şi a verificării existenței unei justificări pentru centralizarea pacienților care suferă complicații postoperatorii.

Descoperiri recente: Este tot mai cunoscută necesitatea evaluării şi estimării ratei imposibilitătii de salvare la nivel de institutii, regional şi național. Numeroşi factori influențează imposibilitatea de salvare, iar toți aceştia ar trebui luați în considerare şi analizați individual. Chirurgia de salvare reprezintă unul dintre aceşti factori. Chirurgia de salvare presupune un context de tratament chirurgical de urgență.

Concluzii: Măsurarea ratei de imposibilitate de salvare ar trebui să devină un standard în programele de îmbunătățire a calitătiii. Implementarea tuturor factorilor clinici şi organizatorici implicați este cheia obținerii unor rezultate mai bune. Gradul de pregătire pentru chirurgia de salvare reprezintă un pilon principal în acest proces. Centralizarea datelor privind managementul, auditul şi comunicarea este la fel de importantă precum centralizarea pacienților. 
Cuvinte cheie: complicații postoperatorii, complicații traumatice, chirurgie de salvare, chirurgie de urgență, centralizare, fragilitate

\begin{abstract}
Purpose of review: To explore the current literature on the failure to rescue and rescue surgery concepts, to identify the key items for decreasing the failure to rescue rate and improve outcome, to verify if there is a rationale for centralization of patients suffering postoperative complications.

Recent findings: There is a growing awareness about the need to assess and measure the failure to rescue rate, on institutional, regional and national basis. Many factors affect failure to rescue, and all should be individually analyzed and considered. Rescue surgery is one of these factors. Rescue surgery assumes an acute care surgery background.

Summary: Measurement of failure to rescue rate should become a standard for quality improvement programs. Implementation of all clinical and organizational items involved is the key for better outcomes. Preparedness for rescue surgery is a main pillar in this process. Centralization of management, audit, and communication are important as much as patient centralization.
\end{abstract}

Key words: postoperative complications, trauma complications, rescue surgery, acute care surgery, centralization, frailty

\section{Introduction}

The concept of failure to rescue (FTR) in recovering patients with complications after surgery is not new. In 1992, Silber and coworkers (1) addressed the issue of hospital and patient characteristics associated with post operative mortality, analyzing some of the factors related to failure to rescue. In the last decade, many authors have reexplored this field $(2-4)$. This renovated interest is due to many reasons: health system costs, need to implement quality improvement programs, awareness and effectiveness of the centralization in many surgical areas (including trauma), emerging of the acute care surgery specialization, and the new rescue surgery concept.

Aim of this review is to introduce and detail the concepts of failure to rescue and rescue surgery, analyze the key items for decreasing the FTR rate and improve outcomes, address the issue of centralization of postoperative complicated patients, and identify pitfalls and open issues.

\section{Failure to Rescue Concept}

Failure to rescue can be defined as the mortality rate following in-hospital complications. In Table 1 some definitions reported in literature are summarized, adding a blended and more comprehensive understanding to this concept (5-10).

Death after surgery can be due to both general and surgical related complications (Table 2). Concerning the latter, sepsis and shock are the umbrella that covers the vast majority of specific postoperative complications, including suture breakdown, anastomotic leakages, intra-abdominal and intra-cavitary infection, and postoperative bleeding.

Two aspects of the definition of failure to

Table 1. Definitions of the failure to rescue concept

- Mortality rate following in-hospital complication

- In-hospital death after 1 or more postoperative complications

- Conditional probability of death after a complication

- Death after a serious, potentially preventable complication

- Ratio deaths after complications / pts with complications 
Table 2. Cause of death assumed in the FTR definitions

\begin{tabular}{l}
\hline DVT/PE \\
Sepsis (including leakages) \\
Gl bleeding \\
Myocardial Infarction \\
Ac. Kidney Injury \\
Pneumonia \\
Resp. failure \\
Shock (incl. postop. bleeding) \\
\hline
\end{tabular}

rescue are paramount: death should be potentially preventable and it should be related to one or more complications (11).

The institutional FTR rate measures the ability of a hospital to identify and manage complications by "rescuing" vulnerable patients, and is considered a Hospital quality index. The milestone paper of Ghaferi et al. (11) analyzed more than 200.000 Medicare patients undergoing six elective major surgical operations. The study ranked Hospitals on the basis of risk-adjusted mortality rates. The incidence of complications was not statistically different in high performing vs. low-performing hospitals, but the resulted difference in mortality was related to complication management. In other words, low-performing hospitals had a higher FTR rate of patients with complications (12). The merit of these analyses is to highlight that postoperative mortality is strictly related to the ability of hospitals and teams to effectively rescue patients from complications.

FTR has been endorsed as a performance benchmark in general surgery by the US National Quality Forum and adopted by the US Agency of Health Care Research and Quality as an indicator of patient safety (13). It is nowadays considered an indicator of quality for assessing surgical results (3).

In Table 3 the factors affecting FTR in different ways are listed.

\section{Failure to Rescue in Elective Surgery}

The impact of FTR rate and outcomes has been evaluated in many papers concerning elective major operations. Weledji and Verla (5) recently published a review on failure to rescue from
Table 3. Factors affecting FTR

\begin{tabular}{l}
\hline Surgeon volume / Hospital volume \\
Hospital resources / characteristics \\
Teaching vs. non teaching H \\
Regional organization \\
Nurse team quality \\
Patient age \\
Frailty (pts) \& Frailty volume per H \\
Concurrent cancer diagnosis \\
Type of operation (LAP vs. Open) \\
\# of complications \\
Team Working / Non technical skills \\
Non trauma / trauma pts \\
\hline
\end{tabular}

early critical complications in oesophageal and gastric surgery for malignancies. They firstly addressed the issue of rescuing patients from surgery general complications, which include systematic attention to perioperative optimization, risk stratification, operative anaesthetic management, postoperative care, and rescue of respiratory complications. The analysis of all specific procedure-related complications (anastomotic leak, chylothorax, conduit necrosis, acute diaphragmatic herniation, recurrent laryngeal nerve injury for oesophagectomy; becomes, haemorrhage, duodenal stump leak, anastomotic leak, pancreatic fistula, intra-abdominal sepsis for gastrectomy) show how many factors can affect both early outcome and long-term survival.

In the era of laparoscopic surgery, surgical approach can play a role in FTR rate. Tu et al. (14) analyzed the records of 4124 patients who underwent open or laparoscopic gastrectomy for neoplasia. FTR rate was significantly lower in patients submitted to laparoscopic resections (2.1 vs. $7.6 \%, \mathrm{p}=0.008)$

Failure to rescue has been also explored in the field of colorectal surgery (15-17).

Ko et al (16) analyzed 220,369 patients who underwent colectomy at teaching and nonteaching Hospitals. Overall mortality was $3.7 \% ; 96 \%$ of deaths were attributable to at least one FTR event. No differences in both FTR rate and overall mortality were shown between teaching and non-teaching Hospitals.

A Dutch group explored FTR rate after colorectal cancer surgery in a large national 
series $(4,17)$. A total of 25,591 patients from 92 hospitals were included. The FTR rate was 0-39\%. Hospital type and volume were not independently associated with FTR rates. Only the lowest level of ICU facilities was independently associated with higher FTR rates. Not surprisingly, FTR was significantly increased in patients with anastomotic leak in a series of 30,101 elective colectomies of the ACS NSQIP database (18). Among the 3.7\% suffering an anastomotic leak, FTR was $6 \%$, compared with only $1 \%$ in the remaining population $(\mathrm{p}<0.001)$.

Failure to rescue has recently been investigated in transplantations. Cramm et al (6) first evaluated this item in a population of 2,330 pediatric patients undergoing primary liver transplants at 21 medical centers, from the Study on Pediatric Liver Transplantation database. They also introduced the extended concept of FTRg (Failure to rescue a graft). This preliminary study showed that FTR can be a useful quality improvement tool for the field of transplantation.

Pancreatic surgery and FTR has been also investigated $(19,20)$. The review of more than 14,557 patients from the ACS NQIPS database for pancreatic resections, showed that patients accumulating additional complications after an initial one were at higher risk for FTR (68.6\% vs. 31.3\%, p<0.001) (21). Analyzing a total of 35,986 patients submitted to pancreatic resections, Amini et al (19) found FTR was more common at low volume (LV) $(12.0 \%)$ and intermediate volume (IH) $(8.5 \%)$ hospitals compared with high volume (HV) hospitals (6.4\%). The improvement in FTR over time was higher at LV and IV hospitals vs. HV hospitals $(p=0.001)$. These data, once more, seem to assign more importance to the ability to deal and rescue complicated patients than to the hospital volume for a specific surgical procedure per se.

The relationships between the number of complications, FTR and mortality has also been investigated. Massarweh et al. (22) performed a retrospective cohort study of 266,101 patients within the Veterans Affairs Surgical Quality Improvement Program (2000-2014) who underwent a high-mortality inpatient general, vascular, or thoracic procedures. They evaluated the association between the number of postoperative complications $(0,1,2$, or 3$)$ and the 30-day mortality. Among complicated patients, $60.9 \%$ had only one, but $63.1 \%$ of deaths occurred in those with more than one complication. Failure to rescue increased significantly between patients with one or more complications $(12.0 \%$ vs. $18.1 \%$; trend test $\mathrm{P}<0.001)$, with an incremental impact (6.7\% 1 complica- $^{-}$ tion vs. $26.1 \% \geq 3$ ).

\section{Age, Frailty and Frailty Volume}

One of the main concerns of modern surgical practice and a field of research is the appropriate selection of elder and elder-old patients for surgery, avoiding futile treatment (23-25). The elderly are intuitively at major risk for postoperative morbidity and mortality. Govaert et al, on behalf of the Dutch value based healthcare study group (26), reviewed all colorectal cancer procedures performed in 29 Dutch hospitals between 2010 and 2012. They compared outcome and costs of colorectal surgery between $9130<$ 85-yr-old patients vs. 783 oldest-old (> 85 yr). Oldest-old had longer hospital stays (LOS) (11.3 vs. $13.2, \mathrm{p}<0.001)$, more severe complications $(21.8 \%$ vs. $29.0 \%, \mathrm{p}<0.001)$, higher mortality $(3.0 \%$ vs. $10.7 \%, p<0.001)$ and higher failure to rescue rate $(13.9 \%$ vs. $37.0 \%, \mathrm{p}<0.001)$. These unfavorable data did not affect the overall hospital costs.

Frailty, defined as an aggregate expression of risk of adverse outcomes due to age- and disease-related deficits that accumulate across multiple domains, seems more related to FTR than age itself $(27,28)$. The rationale is that frailty increases the risk for adverse postoperative outcomes, and outcomes are generally better in hospitals performing large numbers of complex surgery.

McIsaac and coworkers (29) performed a retrospective population-based cohort study on a series of 63,381 frail patients on multiple data sets in Ontario, comparing the association of hospital volume of frail surgical patients cared for and 30-day mortality, after 
elective non cardiac operations. Adjusted survival was significantly improved in the highest volume quintile compared to the lowest: hazard ratio 0.51 (95\% CI, 0.35-0.74). This study highlights survival among frail patients is best in medical centers that care for large numbers of frail surgical patients: usualness to deal with critical patients might be more important than volume itself.

\section{FTR and Hospital Characteristics}

According to an already mentioned study, even if a higher number of complications is expected, teaching and non-teaching hospitals showed the same mortality and FTR rate after elective colorectal surgery (16). In a wider retrospective analysis on Medicare database 2007-2010, Sheetz et al (30) found FTR rates varied up to eleven-fold between very high and very low mortality Hospitals. They identified patients undergoing colectomy, pancreatectomy, esophagectomy, abdominal aortic aneurysm repair, lower-extremity revascularization, or lower extremity amputation. General (colectomy, pancreatectomy, esophagectomy) and vascular (AAA repair, LE revascularization, LE amputation) operations were combined in order to allow generalizability of the results. The number of hospitals included was very high (from 1,681 for esophagectomy to 3,827 for colectomy). Teaching status (OR range: 1.08-1.54), high hospital technology (OR 1.08-1.58), increasing nurse-topatient ratio (OR 1.02-1.14), and presence of more than 20 ICU beds (OR 1.09-1.62) significantly influenced FTR rates.

They argued these macro-system factors can explain only a small proportion of the differences between hospitals. This suggests that micro-system characteristics, such as hospital culture and safety climate, might play a more important role in decreasing FTR rate in each hospital.

\section{Team Working and FTR}

Nursing, communication, safety-culture and team working can affect FTR rate. Relationships between safety-related behaviour and FTR have not been extensively studied yet. Anyway, communication among professionals in and between ICU and inpatient wards, and the institution of rapid response teams are considered critical in the prompt detection and the effective management of patients with surgical complications (7). Unfortunately, in the acute care setting there is a scarcity of data and evidence-based know-how for the implementation of teams. Nurses play a fundamental role. Rao et al (31) analyzed survey responses from 20,684 staff nurses across 570 hospitals. They found each additional point on the nurse autonomy scale was associated with 19\% lower odds of 30-day mortality $(p<0.001)$ and $17 \%$ lower odds of FTR $(p<0.01)$. Hospitals with lower levels of nurse autonomy place their surgical patients at an increased risk for mortality and FTR.

\section{FTR in Trauma Patients}

After an initial interest in the application of this concept in trauma setting $(32,33)$, some concerns about the potential use of FTR as a quality benchmark in trauma were raised $(9,8)$. The reason is the fact preventable death is a long lasting issue in trauma care quality assessment, and the effectiveness of trauma systems are usually measured on the decreasing rate of preventable deaths. It could therefore become difficult to differentiate preventable deaths from preventable negative outcome of one or more complications (FTR) occurred after trauma.

Kuo et al. (9) performed an analysis of 26,557 patients managed for major trauma at a Level I Trauma Center at Penn University between 2005-2015. Among the 2,735 complicated patients, 359 died, registering an FTR rate of $13.2 \%$. Among FTR deaths, $75.6 \%$ were judged non-preventable, $18.1 \%$ were judged potentially preventable, and only $6.1 \%$ were judged to be preventable by an institutional peer review panel.

The FTR measure in trauma setting may capture many patients who were unable to be rescued, even with optimal clinical care.

Notwithstanding, the interest of FTR in trauma could be of paramount interest in the elderly population. Barmparas et al. (34) 
compared FTR vs. FTRE (FTR in the elderly) over a retrospective review of Trauma Databank (NTDB) research data sets in 2010 and 2011. Increase in FTRE predicted a significantly higher mortality when centers with FTRE $\leq 5 \%$ were compared to those with 5-14\% (AOR: 1.05, $\mathrm{p}=0.031$ ) and $\geq 15 \%$ (AOR: $1.13, \mathrm{p}<0.001$ ).

\section{Rescue Surgery, FTR and Acute Care Surgery}

Research, retrospective studies and reviews have clearly shown that the incidence of complications at high-performing versus low-performing hospitals is not as different as one would intuitively suspect. Failure to rescue rates varied widely across hospitals for all procedures and were highly correlated with postoperative mortality. Difference is in the ability to save the patient who has developed a major complication, the so called initial "seminal" complication. In other words, a high-performing hospital rescues the patient from the complication, the low-performing hospital does not.

Surgeon experience on dealing with critically ill patients is also crucial. Peitzman and the group of UPMC of Pittsburgh first put on the spot the surgical rescue concept as one of the main pillars of acute care surgery. (34) Rescue surgery was essentially defined as "pulling the patient from the fire after they have developed a complication from surgical or medical care". The same group (35) tried to better identify the area of interest of the specific skills required for effectively perform rescue surgery. They analyzed the data of a prospective, electronic medical record-based Acute Care Surgery registry at their Centre, screening by ICD-9 codes acute surgical complications requiring an operative or interventional procedure. Long-term outcomes were also retrieved. Out of 2,410 patients, 320 (13\%) required "surgical rescue". Around 50\% had sepsis, obstruction or hemorrhage. More than $50 \%$ of interventions were bowel resections, infection control or bleeding control. These results make clear the acute care surgeon, used to deal with critical patients, could be the best specialist for taking care, in a multidisciplinary team, about postoperative complica- tions, very often related to sepsis and bleeding. Very recently, Gui and coworkers (36) performed a 12 item survey on rescue surgery, addressed to the members of the Italian Society for Trauma and Emergency Surgery (SICUT). Comparing the results of the Pittburgh series (35) with the Italian survey (36), the source of patients requiring rescue surgery was not so different. In fact, they respectively came from their own Services in 36 vs. $50 \%$ of cases, from the other Services in the same hospital in 38 vs. $30 \%$, and were referred from other hospitals in 26 vs. $20 \%$ of cases. It is evident that around one third was generated from general and specialistic surgical departments in their own hospitals, rising the need for a strong and continuous maintenance of skills and background in elective general surgery for the acute care surgery teams. The recently published observation that FTR rate incrementally increases according to the number of complications (22), makes evident the sickest patient requires the team most experienced in managing complex cases with a "rescue" mindset.

\section{Centralization of Postoperative Complications}

Surgeon and hospital experience are intimately associated with outcomes $(37,38)$ The same is for volume of surgery and specialization $(39,40)$ with some authors even advocating a pledge for centralization. Trauma systems, after all, are a clear example of the organizational effort to improve outcomes through a concentration of the sickest patients in more equipped hospitals with experienced professionals.

To centralize the management of postoperative complications is even harder than concentrate certain pathologies in specialized hospitals. It is in fact a multifactorial issue of organization, surgical and hospital ego, relationships between hospitals and surgeons. Notwithstanding, critically ill complicated patients need a centralized management, with a multidisciplinary team imbued by common goals, with someone (person and/or organized process) leading toward a unique direction. What is usually catastrophic for the complicated patient is the lack of a red wire, of a 
precise hand-over among providers, and of a systematic critical reappraisal of the evolution and choices. We could affirm that "centralization for postoperative complicated patients is not a location, is a philosophy". A philosophy requiring leaderships, organization and systematic audit.

\section{Beyond FTR}

Failure to rescue is certainly an underestimated factor in perioperative medicine accounting for or at least being involved in the development of postoperative mortality. There is a major potential for improvement. Boehm et al. (10) analyzed German data and considered that with 14 million surgical procedures per year, a postoperative mortality of approximately $1 \%$ and an avoidable FTR rate of $40 \%$, there are an estimated 60,000 preventable deaths per year in Germany. It becomes mandatory to expand preoperative risk assessment, to strategically prevent the post-operative complications, to implement systems for the early detection of postoperative complications, and to improve the effective and prompt medical and surgical (the rescue surgery) treatment of postoperative complications. Trauma care quality improvement program could serve as paradigm for developing this process (41).

Processes in place in hospitals with low FTR rates should be converted to best practices (structural or process measures), to be transferred to other hospitals in order to improve their FTR rate $(42,43)$.

Suggested strategies are demanding: understanding of the single hospital system, caregivers, available resources; implementing process methods to effectively learn from failure to rescue events; improving hospital safety culture $(30,44)$.

\section{Conclusions}

The systematic use of FTR rate as benchmark of outcome and results can help to evaluate the difference between medical centers, and is a useful quality improvement tool in single centers, giving a more objective feedback on actions established in different periods.

Rescue surgery, as part of the FTR rate improvement and one of the pillars of the acute care surgery, requires surgeons with a specific background on critical care and frail patient management, awareness of technical details of elective surgery, and knowledge of the impact of the rescuing strategy chosen on the global outcome of the underlining oncologic disease when necessary.

Centralization is a management philosophy more than a location, when facing complicated frail patients. When and where centralization of patients is not possible, it remains mandatory to implement and pursue centralization of clinical management, audit, and communication with patients, relatives and among the team.

\section{Human and Animal Rights}

This article does not contain any studies with human or animal subjects performed by any of the authors.

\section{Authorship}

All Authors confirm that they have met the criteria for authorship as established by the International Committee of Medical Journal Editors.

\section{Conflict of Interest}

All Authors state to have no conflict of interest to declare.

\section{References}

1. Silber JH, Williams SV, Krakauer H, Schwartz JS. Hospital and patient characteristics associated with death after surgery. A study of adverse occurrence and failure to rescue. Med Care. 1992; 30(7):615-29.

2. Silber JH, Romano PS, Rosen AK, Wang Y, Even-Shoshan O, Volpp KG. Failure-to-rescue: comparing definitions to measure quality of care. Med Care. 2007;45(10):918-25.

3. Aguayo-Albasini JL, Pares D. Failure to rescue: An indicator of quality necessary to assess the surgical results. Rev Calid Asist. 2016;31(3):123-5. doi:10.1016/j.cali.2016.03.004.

4. Henneman D, Snijders HS, Fiocco M, van Leersum NJ, Kolfschoten NE, Wiggers T et al. Hospital variation in failure to rescue after colorectal cancer surgery: results of the Dutch Surgical Colorectal Audit. Ann Surg Oncol. 2013;20(7):2117-23.

5. Weledji EP, Verla V. Failure to rescue patients from early critical complications of oesophagogastric cancer surgery. Ann Med Surg (Lond). 2016;7:34-41. doi:10.1016/j.amsu.2016.02.027. 
6. Cramm SL, Waits SA, Englesbe MJ, Bucuvalas JC, Horslen SP, Mazariegos GV et al. Failure to Rescue as a Quality Improvement Approach in Transplantation: A First Effort to Evaluate This Tool in Pediatric Liver Transplantation. Transplantation. 2016;100(4):8017. doi:10.1097/TP.0000000000001121.

7. Ghaferi AA, Dimick JB. Importance of teamwork, communication and culture on failure-to-rescue in the elderly. $\mathrm{Br} \mathrm{J}$ Surg. 2016; 103(2):e47-51. doi:10.1002/bjs.10031.

8. Holena DN, Earl-Royal E, Delgado MK, Sims CA, Pascual JL, Hsu JY et al. Failure to rescue in trauma: Coming to terms with the second term. Injury. 2016;47(1):77-82. doi:10.1016/j.injury.2015. 10.004

9. Kuo LE, Kaufman E, Hoffman RL, Pascual JL, Martin ND, Kelz RR et al. Failure-to-rescue after injury is associated with preventability: The results of mortality panel review of failure-to-rescue cases in trauma. Surgery. 2017;161(3):782-90.

10. Boehm O, Pfeiffer MK, Baumgarten G, Hoeft A. (Perioperative risk and mortality after major surgery). Anaesthesist. 2015;64(11):81427. doi:10.1007/s00101-015-0110-y.

11. Ghaferi AA, Birkmeyer JD, Dimick JB. Complications, failure to rescue, and mortality with major inpatient surgery in medicare patients. Ann Surg. 2009;250(6):1029-34.

12. Ghaferi AA, Birkmeyer JD, Dimick JB. Variation in hospital mortality associated with inpatient surgery. The New England journal of medicine. 2009;361(14):1368-75. doi:10.1056/NEJMsa0903048.

13. Indicators AfHRaQ. Patient Safety Indicators: Technical Specidications. 3.0. 2013

14. Tu RH, Lin JX, Zheng CH, Li P, Xie JW, Wang JB et al. Complications and failure to rescue following laparoscopic or open gastrectomy for gastric cancer: a propensity-matched analysis. Surg Endosc. 2017;31(5):2325-37. doi:10.1007/s00464-016-5235-9.

15. Almoudaris AM, Burns EM, Mamidanna R, Bottle A, Aylin P, Vincent $C$ et al. Value of failure to rescue as a marker of the standard of care following reoperation for complications after colorectal resection. Br J Surg. 2011:98(12):1775-83. doi:10.1002/bjs.7648.

16. Ko A, Aquino L, Melo N, Alban RF. Surgical outcomes and failure-torescue events after colectomy in teaching hospitals: a nationwide analysis. Am J Surg. 2016;212(6):1133-9.

17. Henneman D, van Leersum NJ, Ten Berge M, Snijders HS, Fiocco M, Wiggers $\mathrm{T}$ et al. Failure-to-rescue after colorectal cancer surgery and the association with three structural hospital factors. Ann Surg Oncol. 2013;20(11):3370-6. doi:10.1245/s10434-013-3037-z.

18. Tevis SE, Carchman EH, Foley EF, Heise CP, Harms BA, Kennedy GD. Does Anastomotic Leak Contribute to High Failure-to-rescue Rates? Ann Surg. 2016;263(6):1148-51. doi:10.1097/SLA.0000000000001409.

19. Amini N, Spolverato G, Kim Y, Pawlik TM. Trends in Hospital Volume and Failure to Rescue for Pancreatic Surgery. J Gastrointest Surg. 2015;19(9):1581-92. doi:10.1007/s11605-015-2800-9.

20. Ghaferi AA, Osborne NH, Birkmeyer JD, Dimick JB. Hospital characteristics associated with failure to rescue from complications after pancreatectomy. J Am Coll Surg. 2010;211(3):325-30. doi:10.1016/ j.jamcollsurg.2010.04.025

21. Varley PR, Geller DA, Tsung A. Factors influencing failure to rescue after pancreaticoduodenectomy: a National Surgical Quality Improvement Project Perspective. J Surg Res. 2017;214:131-9. doi:10.1016/j.jss.2016.09.005.

22. Massarweh NN, Anaya DA, Kougias P, Bakaeen FG, Awad SS, Berger DH. Variation and Impact of Multiple Complications on Failure to Rescue After Inpatient Surgery. Ann Surg. 2017;266(1):59-65. doi:10.1097/SLA.0000000000001917.

23. Theou 0, Brothers TD, Mitnitski A, Rockwood K. Operationalization of frailty using eight commonly used scales and comparison of their ability to predict all-cause mortality. J Am Geriatr Soc. 2013; 61(9):1537-51. doi:10.1111/jgs.12420.

24. Sternberg SA, Bentur N, Abrams C, Spalter T, Karpati T, Lemberger $\mathrm{J}$ et al. Identifying frail older people using predictive modeling. Am J Manag Care. 2012;18(10):e392-7.

25. Costa G MG, Balducci G, Frezza B, Fransvea P, Nigri G, Stagnitti F, et al. Frailty and emergency surgery in the elderly: Protocol of a prospective, multicenter study in Italy for evaluating perioperative outcome (the FRAILESEL Study). F1000 Research. 2017;6:1162.

26. Govaert JA, Govaert MJ, Fiocco M, van Dijk WA, Tollenaar RA Wouters MW et al. Hospital costs of colorectal cancer surgery for the oldest old: A Dutch population-based study. Journal of surgical oncology. 2016;114(8):1009-15. doi:10.1002/jso.24428.

27. Fried LP, Tangen CM, Walston J, Newman AB, Hirsch C, Gottdiener $J$ et al. Frailty in older adults: evidence for a phenotype. J Gerontol A Biol Sci Med Sci. 2001;56(3):M146-56.

28. Oakland K, Nadler R, Cresswell L, Jackson D, Coughlin PA. Systematic review and meta-analysis of the association between frailty and outcome in surgical patients. Ann R Coll Surg Engl. 2016;98(2):80-5. doi:10.1308/rcsann.2016.0048.

29. Mclsaac DI, Wijeysundera DN, Huang A, Bryson GL, van Walraven C. Association of the Hospital Volume of Frail Surgical Patients Cared for with Outcomes after Elective, Major Noncardiac Surgery: A Retrospective Population-based Cohort Study. Anesthesiology. 2017:126(4):602-13. doi:10.1097/ALN.0000000000001536.

30. Sheetz KH, Dimick JB, Ghaferi AA. Impact of Hospital Characteristics on Failure to Rescue Following Major Surgery. Ann Surg. 2016;263(4):692-7. doi:10.1097/SLA.0000000000001414.

31. Aiken LH, Clarke SP, Sloane DM, Lake ET, Cheney T. Effects of hospital care environment on patient mortality and nurse outcomes. J Nurs Adm. 2008;38(5):223-9.

32. Haas B, Gomez D, Hemmila MR, Nathens AB. Prevention of complications and successful rescue of patients with serious complications: characteristics of high-performing trauma centers. J Trauma. 2011;70(3):575-82.

33. Glance LG, Dick AW, Meredith JW, Mukamel DB. Variation in hospital complication rates and failure-to-rescue for trauma patients. Ann Surg. 2011;253(4):811-6.

34. Peitzman AB, Sperry JL, Kutcher ME, Zuckerbraun BS, Forsythe RM, Billiar TR et al. Redefining acute care surgery: Surgical rescue. J Trauma Acute Care Surg. 2015;79(2):327.

35. Kutcher ME, Sperry JL, Rosengart MR, Mohan D, Hoffman MK, Neal $M D$ et al. Surgical rescue: The next pillar of acute care surgery. $J$ Trauma Acute Care Surg. 2017:82(2):280-6.

36. Gui D, Cozza V, Pepe G, Di Grezia M, La Greca A, Magalini S. Present and future of emergency surgery as independent specialty in Italy: is the rescue surgery turning the underdog into a hero? Eur Rev Med Pharmacol Sci. 2017;21(4):899-902.

37. Birkmeyer JD, Siewers AE, Finlayson EV, Stukel TA, Lucas FL, Batista I et al. Hospital volume and surgical mortality in the United States. The New England journal of medicine. 2002;346(15):112837. doi:10.1056/NEJMsa012337.

38. Finks JF, Osborne NH, Birkmeyer JD. Trends in hospital volume and operative mortality for high-risk surgery. The New England journal of medicine. 2011:364(22):2128-37. doi:10.1056/NEJMsa1010705.

39. Chowdhury MM, Dagash H, Pierro A. A systematic review of the impact of volume of surgery and specialization on patient outcome. Br J Surg. 2007:94(2):145-61. doi:10.1002/bjs.5714.

40. Urbach DR. Pledging to Eliminate Low-Volume Surgery. The New England journal of medicine. 2015;373(15):1388-90.

41. Ingraham AM, Haas B, Cohen ME, Ko CY, Nathens AB. Comparison of hospital performance in trauma vs emergency and elective general surgery: implications for acute care surgery quality improvement. Arch Surg. 2012;147(7):591-8. doi:10.1001/archsurg.2012.71.

42. Hornor MA, Bilimoria KY. Moving beyond failure to rescue. Surgery. 2017;161(3):791-2. doi:10.1016/j.surg.2016.11.012.

43. Ingraham AM, Greenberg CC. Failure to rescue and preventability: Striving for the impossible? Surgery. 2017;161(3):793-4. doi:10.1016 /j.surg.2016.11.013.

44. Ghaferi AA, Dimick JB. Understanding failure to rescue and improving safety culture. Ann Surg. 2015;261(5):839-40. doi:10.1097/ SLA.0000000000001135 